\title{
Solution Validation for a Double Façade Prototype
}

\author{
Pau Fonseca i Casas ${ }^{1, *}$, Antoni Fonseca i Casas ${ }^{1}$, Nuria Garrido-Soriano ${ }^{1}$, Alfonso Godoy ${ }^{1}$, \\ Wendys-Carolina Pujols ${ }^{2}$ and Jesus Garcia ${ }^{2}$ \\ 1 Computing Laboratory, Universitat Politècnica de Catalunya, 08034 Barcelona, Spain; \\ antoni.fonseca@necada.com (A.F.C.); nuria.garrido@upc.edu (N.G.-S.); alfonso.godoy@upc.edu (A.G.) \\ 2 ACCIONA Infraestructuras (S.L.), 28108 Madrid, Spain; wencarolina.pujols@gmail.com (W.-C.P.); \\ jesus.gdominguez@gmail.com (J.G.) \\ * Correspondence: pau.fonseca@upc.edu; Tel.: +34-934-017-732
}

Received: 9 October 2017; Accepted: 12 November 2017; Published: 1 December 2017

\begin{abstract}
A Solution Validation involves comparing the data obtained from the system that are implemented following the model recommendations, as well as the model results. This paper presents a Solution Validation that has been performed with the aim of certifying that a set of computer-optimized designs, for a double façade, are consistent with reality. To validate the results obtained through simulation models, based on dynamic thermal calculation and using Computational Fluid Dynamic techniques, a comparison with the data obtained by monitoring a real implemented prototype has been carried out. The new validated model can be used to describe the system thermal behavior in different climatic zones without having to build a new prototype. The good performance of the proposed double façade solution is confirmed since the validation assures there is a considerable energy saving, preserving and even improving interior comfort. This work shows all the processes in the Solution Validation depicting some of the problems we faced and represents an example of this kind of validation that often is not considered in a simulation project.
\end{abstract}

Keywords: solution validation; simulation; optimization; double façade; energy saving; energy demand

\section{Introduction}

In the framework of the project JSEED [1,2], a set of experiments are conducted to obtain an optimal solution for a double façade prototype, with the aim of improving the building's energy savings. In order to ensure that the correct decisions are made, a prototype that responds to the parameters selected was built. With this prototype, a comparison between the models and the data that we obtain for the prototype was performed. This allows validation of the methodology and the hypotheses in order to reuse the models in other climatic areas or with other parameters, avoiding the need to build new prototypes. This experience depicts a complete system validation and explains the methodologies used in the development of the project.

The Validation and the Verification of a simulation model are key elements to increase the model confidence [3]. Several techniques can be applied [4,5], and some recommendations can be followed [6]. A conceptual model can help in this process, becoming a central factor to perform this validation $[4,7]$. An example that takes advantage of the power of formal languages to perform the validation of the model can be reviewed in [8], where UML is combined with Petri nets (a formal and unambiguous formalism) in order to define test scenarios to be applied in the simulator. In our approach, we are taking the advantage of formal languages, using Specification and Description Language (SDL) [9] to represent the model allowing an automatic implementation of it, simplifying the verification process. The validation process was done, reviewing with the specialist the model (model validation) and performing a black and white box validation. In this formal representation of the system, all the 
hypotheses that must be tested are described. With the first executions of the model, different tests can be performed, comparing the results with the existing system, if it exists, or, with similar systems or the knowledge that the specialist has, if the system does not exist. To ensure that a simulation model is accurate, Solution Validation must be applied, if possible. The Solution Validation process compares the final implementation (in the system, based on the model results) with the results obtained by the simulation model, "The aim of all modelling and VEV efforts is to try to assure the validity of the final solution; once implemented, it should be possible to validate the implementation against the model's results" [10]. Solution validation assures that the hypotheses are correct and the hypotheses proposed for the formal representation of the system (the model) are also correct and then, can be used on new scenarios with more confidence. Solution Validation is complex because as is stated in [11]: "solution validation can only take place post-implementation of the study's findings"; also, specifically the validation of environmental models is a complex task due to the inherent complexity of the considered elements and the huge amount of data that are going to be used; see [12,13]. Because of this complexity, some work conducted validation analysis in the analysis and the classification of the input data; see [14], or in the sensitivity analysis of the model data; see [15]. But usually no validations are done implying the real system with the proposed modifications, i.e., the Solution Validation, that allows complete understanding if the assumptions are correct or not. The lack of this type of validation in this kind of system is obvious because of two aspects:

1. This validation must be done once the simulation project is finished and once the implementation of the results obtained from the model are applied to the system. This implies that the contractor believes in the model, and now we are going to perform a new validation.

2. The complexity to analyze the modified system in this ambit (environmental area).

In this paper, we analyze the Solution Validation and the methodologies used in the whole development of the Validation Verification and Accreditation (VV \& A) process; see Figure 1 to put this kin the context of a whole simulation project validation cycle. The model is focused on the analysis of the behavior of a building in order to improve its behavior, testing a new façade prototype. Studies that use simulation to analyze the behavior of ventilation exist and have become more and more common; see [16]. Here, we are going to be focused on the validation processes, specifically on system validation. This research area is intensively analyzed because buildings consume around $33 \%$ of energy worldwide; see [17]. This motivates an intensive research in this area, with an increasing applications of Operations Research techniques, to help in the design of environmental processes; see as examples [18-26]. Specifically, with respect buildings, without a calculus of their passive behavior, we cannot achieve a real improvement in the energy savings. The need to obtain the maximum benefit of solar and lighting in winter and heat protection in summer (mostly in temperate and not extreme climates) leads us to develop mixed solutions that enables adaptability depending on the time of year and climate zone. The premise of the project is to design a solution for building openings, mainly for office use, and focuses in different climatic zones of Spain. The project responds to the new European guidelines for energy savings, European directive 2010/31/EC [27] related to the energy efficiency of buildings and the data published by the International Energy Agency [28]. The need to propose solutions that help in the reduction of the energy demand in order to design buildings near NZEB $[29,30]$ is an important premise to be considered in the design of a new prototype of building openings. In the project, a modular system composed by a double façade was developed. The main goal is to create an element that can be adapted easily to different buildings, that offers a good behavior from the point of view of the energy (passive and active), being transformed from a traditional window to a device that provides efficiency and comfort through a controlled operation. 


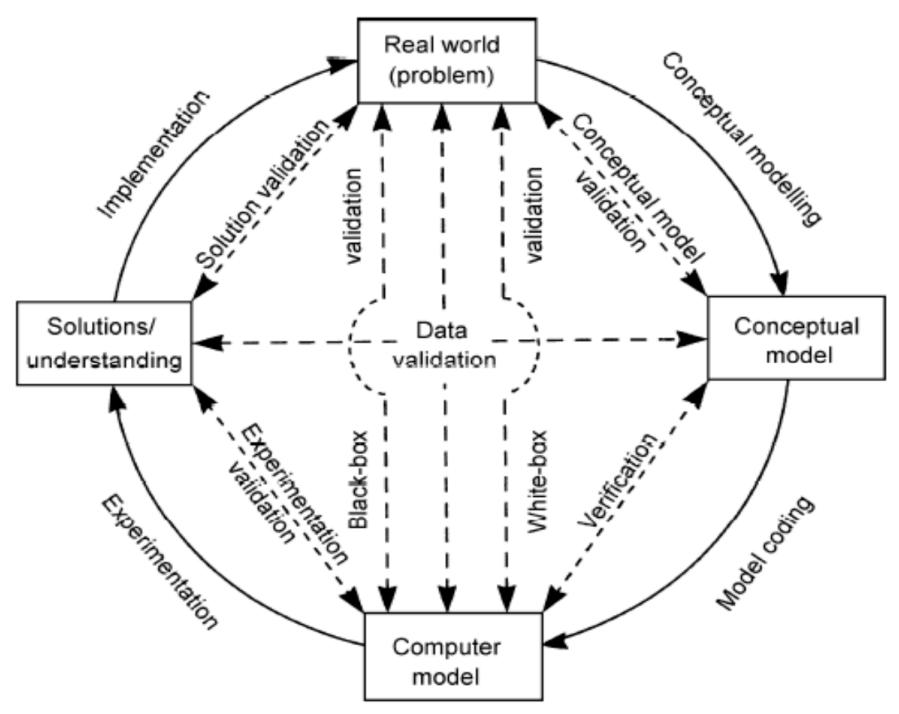

Figure 1. Simulation VV cycle [10].

In the project, we model and implement two prototypes and perform a complete solution validation to test if the proposed assumptions are correct. Solution validation needs a Verified, Validated and Accredited model to start. Those models are the ones that we are going to use to assure that all the whole process followed is correct, and to perform a new Accreditation for such models using a real system. To do so, we use black box validation techniques [11], where the results of the model will be compared with the data obtained for the system.

\section{The Model}

Major concerns in this kind of simulation are the climatic conditions to be used in the simulation model. In our case, we base this on [31]. Since the climatic zone selected is Seville, due to the situation of the Test Cell prototype, the IWEC database to be used will be Sevilla.epw based on the International Weather Climate [32].

Once the climatic conditions are fixed, the thermal comfort conditions need to be defined. To do so, the data provided by RD 1826/2009, published on the BOE of 11 December 2009 were used. These data supersede RITE (Reglamento de Instalaciones Térmicas de los Edificios), in the instruction RITE Section 3, and the RITE Section 4. Table 1 shows the references used for the comfort in this project.

Table 1. Reference for the comfort data [33].

\begin{tabular}{ccc}
\hline Offices & Temp. $\left({ }^{\circ} \mathrm{C}\right)$ & $\%$ HR \\
\hline Summer Inside & 26 & $45-60$ \\
Winter Inside & 21 & $40-50$ \\
\hline Dwellings & Temp. $\left({ }^{\circ} \mathrm{C}\right)$ & $\%$ HR \\
Summer Inside & 25 & 50 \\
Winter Inside & 21 & 50 \\
\hline
\end{tabular}

Regarding the materials used in the definition of the simulation models, we always consider the prototype that will be constructed in order to simplify the solution validation, but without compromising the universality of the results that we can obtain. In that sense, although perimeter walls could have been simulated as adiabatic, we preferred to approximate the simulation model to the experimental study prototype. Thermal transmittance requirements for walls were $0.1 \mathrm{~W} / \mathrm{m}^{2} \cdot \mathrm{K}$ (30 cm thick rock wool); on the one hand, the resulting reference data (the data used to perform the 
comparison between the different simulations) do not increase significantly and, on the other hand, we prepare the virtual design with materials and their real properties.

Another important aspect to be considered is parameterization of the internal loads, the occupation and infiltration. To do so, we use the data provided by the IDAE and regulation of heating systems in buildings and the CTE [34]. To determine the infiltration, the data provided by the CTE were used, related to $<27 \mathrm{~m}^{3} / \mathrm{h} \cdot \mathrm{m}^{2}$.

Another important aspect in the model is the glass materials to be used; see Table 2.

Table 2. Glass materials used in the simulation models. Source [35].

\begin{tabular}{cccccc}
\hline Name Glass Material & Concept & $\begin{array}{c}\text { Solar } \\
\text { Transmission } \\
\text { (SHGC) }\end{array}$ & $\mathbf{U}$ (W/m $\mathbf{m}^{\mathbf{2} \cdot \mathbf{K})}$ & $\begin{array}{c}\text { Direct Solar } \\
\text { Transmission }\end{array}$ & $\begin{array}{c}\text { Light } \\
\text { Transmission }\end{array}$ \\
\hline $\begin{array}{c}\text { FachTe_Glass_FV_SHGC } \\
\text { 0.1, Light transmision }\end{array}$ & photovoltaic plate Schott & 0.1 & 1.1 & - & 0.1 \\
0.1,U 1.1 & & & & & \\
\hline FachTe_Glass_6-8-6 & double glass & 0.5 & 3 & 0.373 & 0.5 \\
FachTe_Glass_3-8-3 & normal glass & 0.828 & 3.087 & 0.813 & 0.839 \\
FachTe_Glass_10-12-10 & low-e glass & 0.559 & 1.89 & 0.418 & 0.71 \\
FachTe_Glass_6-13-6 & solar control glass 6+12+6 & 0.168 & 1.672 & 0.087 & 0.114 \\
FachTe_Glass_6 & simple glass & 0.819 & 5.718 & 0.775 & 0.881 \\
\hline
\end{tabular}

The model incorporates not only the physical aspects needed to define the behavior of the building, but also the legislation, to assure the validity of the proposed solutions in the real context that we are facing.

All these parameters, and the processes that rule the behavior of the building are defined using a formal representation based on Specification and Description Language formalism (SDL). In [36] you can review the details of the model used; in $[37,38]$ an application of this methodology for the simulation analysis is shown. From this specification, a tool named SDLPS [39] allows the execution of the model formalized in SDL, obtaining the solutions without the need to perform a specific implementation. This simplifies the verification process.

The model is focused on analyzing the effects of the design elements over the energy consumption of the building. The proposed model allows us to find the optimal combination that satisfies the requirements and the needs of the design of a building, at both the environmental level and at the economic cost level. Figure 2 the system diagram that rules the behavior of our model is defined.

The model allows us to obtain comparative results, showing the effects of every constructive aspect regarding the total consumption of the building. Starting from there, the user can define different configurations for the design. In each configuration we can change the constructive solutions, the thickness of a wall, the orientation or the meteorology of the location of the building. The optimizer combines all the possible configurations to find a preferred optimal solution. In order to not reinvent the wheel, we use co-simulation techniques, using Energy Plus [40] as an energy consumption calculation engine.

Once the best desired configuration that responds to the objectives of the project is determined, CFD simulations were prepared (computational fluid dynamics software) to reach a more detailed proposal for the constructive solutions to be used (allowing an accurate control of the behavior of the proposed façade). CFD simulations allow analysis of the flows and the stratification of the resulting air, the behavior of the air heating, the façade materials thermal behavior and the space ventilation. Figure 3 shows energy consumption depending on the building orientation. 


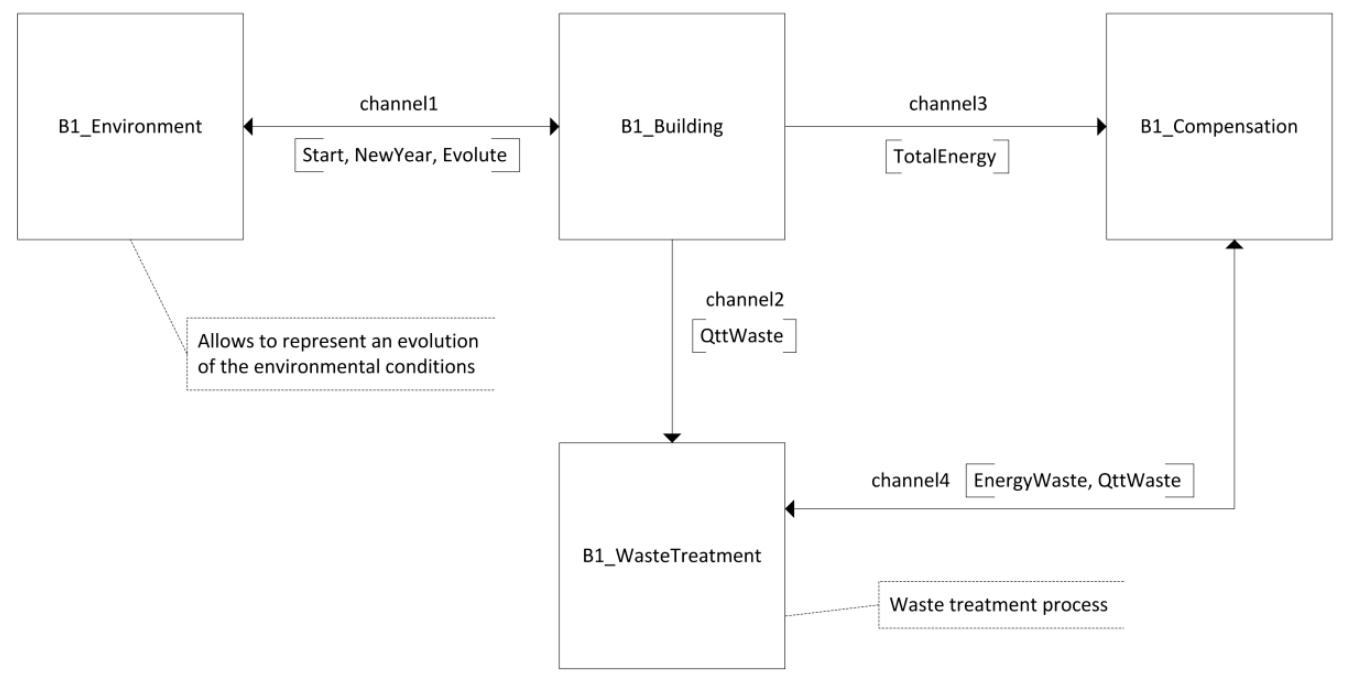

Figure 2. System diagram of the SDL model. The complete model can be reviewed in [36]; the figure only presents the first level of the SDL model that depicts the main blocks that interact in the model (the environment, the building, the compensation elements and the waste treatment systems).

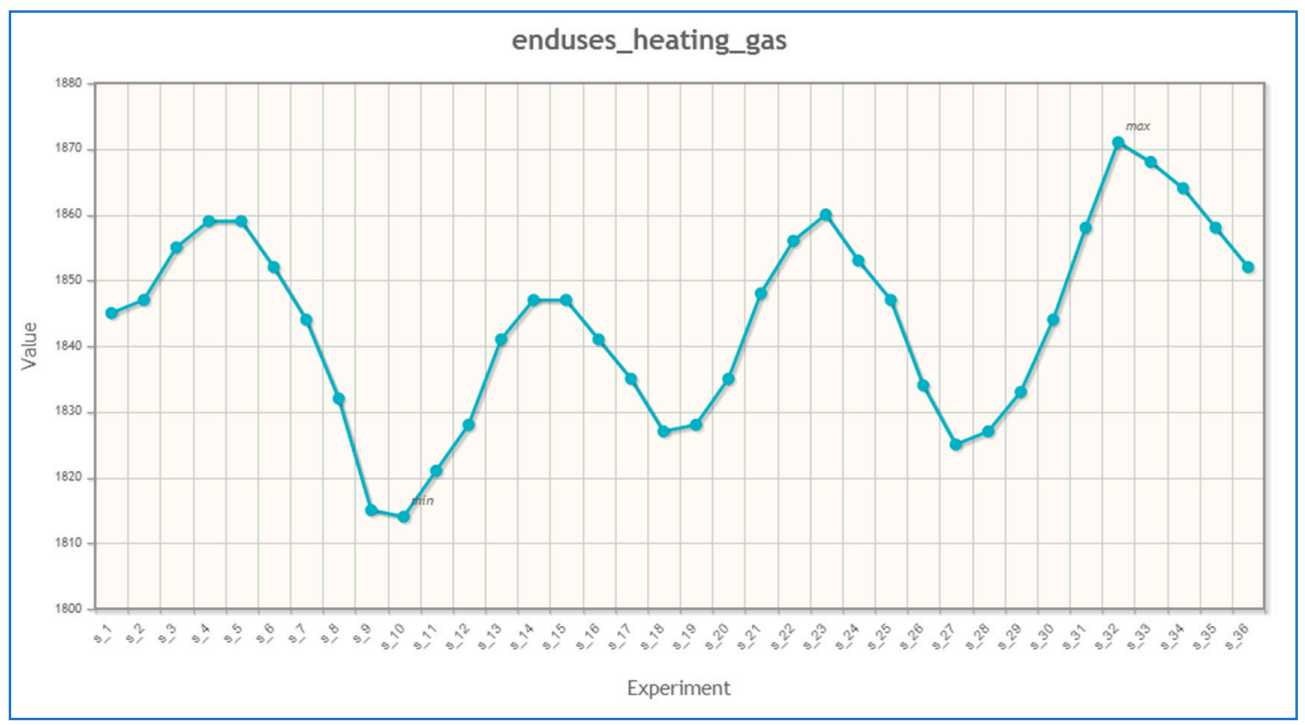

Figure 3. Example of numerical results of the energy consumption depending on the building orientation obtained directly from the model output.

\section{Implementing the Results in the System}

The property, where the prototypes were built, belongs to ACCIONA Infraestructuras, S.L. The placement of prototypes did not present any difficulty, as the land was ready for it. In addition, there was no problem regarding shadows or strong winds.

Two prototypes were built in order to consider two main scenarios. The prototype is a block, similar to a building office, in Seville, south facing, for individual offices. The façade corresponding to the experimental prototype is $2 \mathrm{~m} \times 2 \mathrm{~m}$. The enclosure materials used in the prototype are shown in Table 3. 
The first prototype is intended to be used to compare a double-glazed façade (glass + glass) with double glass + photovoltaic skin façade (see first floor of Figure 4). The second prototype, for the second façade, is composed by a climate system capable of allowing oscillations and thermal variations on the proposed air velocities. This second façade will be analyzed entirely in CFD; 8 scenarios will be executed (allowing the selection of 2 different airflows, 2 boundary conditions and 2 sizes of the air chamber). In this paper, the focus will be on this second prototype.

Table 3. The enclosure materials used in the actual prototype.

\begin{tabular}{clc}
\hline Description & Materials (from Outside to Inside) & Thickness (cm) \\
\hline Exterior & (sheet metal + camera air + battens) + insulation + pre-stressed wooden panel & $0.3+5+8+10$ \\
Interior & Insulation + wood panel + finish & $8+1.5+1.5$ \\
Ceiling & Sheet + camera air + insulation + waterproof sheet + panel wood freestanding & $0.5+5+20+0.3+10$ \\
Door & Access for service space & - \\
Foundation & Wood base + wood leveling screed & variable \\
\hline
\end{tabular}

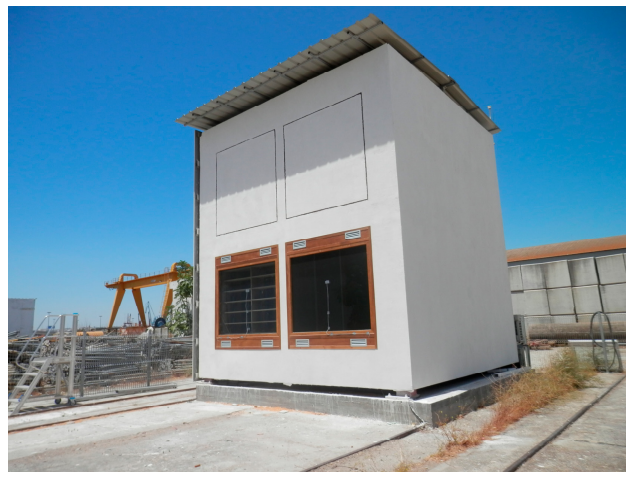

(a)

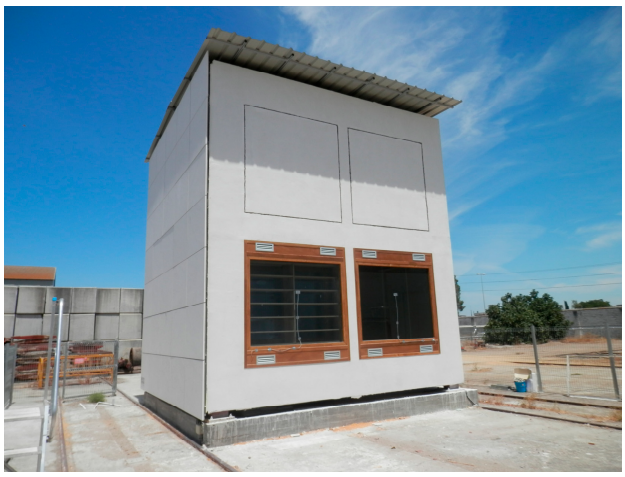

(b)

Figure 4. General view of the prototype solar (a), on the right (b) facing south-east direction.

The prototype is separated from the terrain, about $30-50 \mathrm{~cm}$, to avoid possible heat moisture or gas transfer. The effect on the thermal behavior of a space is very different depending on its contact (or not) with the ground, due to thermal inertia. Therefore, separating the prototype of the land is fundamental to make the correspondence between the model and the prototype as close as possible, especially when the prototype is only one height. Unions and joins have to be made through dry construction, following the pattern or models proposed by the Passivhaus standard certification, in such a way that the thermal bridges and discontinuities in the thermal insulation are avoided at all times.

\subsection{Prototype Sensors}

In order to enable the Solution Validation, information from the system must be obtained in real time. To do so, we add several sensors to the prototype to obtain mainly (i) the evolution of the average temperature of the airflow along the height of the cavity and (ii) a comparison, over time, of interior space against the outside ambient temperature. Next $\mathrm{T}$ Thermocouples were considered more appropriate, since they have a good sensibility, are resistant to oxidation, humidity and external agents, and cover the range of measurements which must be assured.

The distribution of the sensors was defined in order to capture temperature gradients and curves. Since in reality, important $\mathrm{T}$ gradients occur, it is not deemed representative to acquire only a value of $\mathrm{T}$ (since this varies greatly with the position). The sensors applied were to measure (i) Temperature and Humidity Relative (in the central section in different heights); (ii) superficial radiation, on envelope walls and the façade of the study; (iii) speed of the indoor air and (iv) illumination levels. We also 
measured the climatic changes on the outside of the prototype. Figure 5 shows the proposed sensor system distribution for the prototypes.

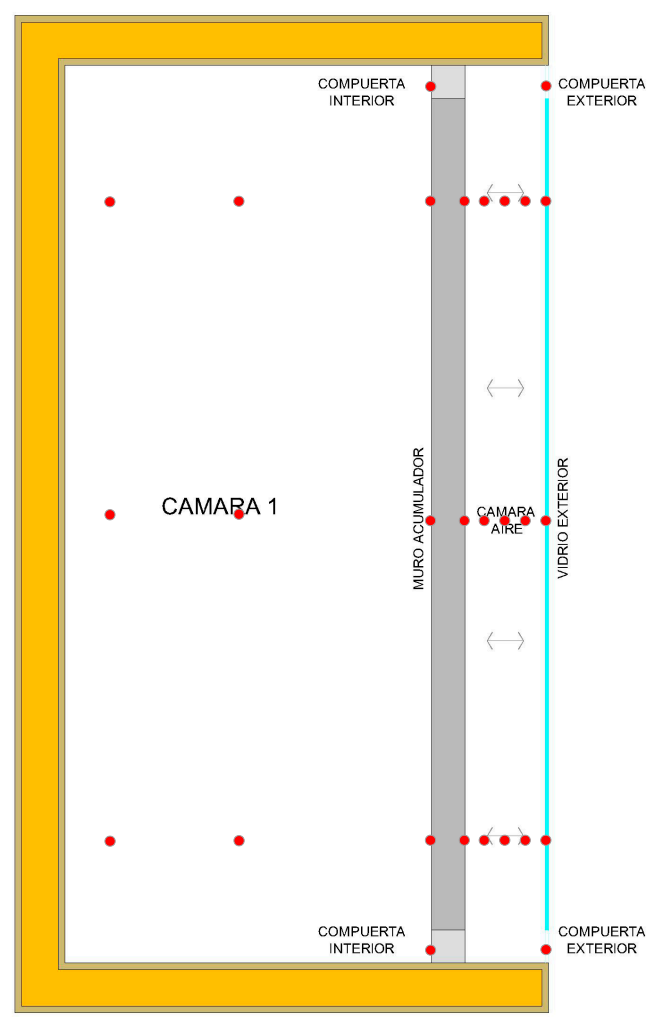

SECCION CAMARA 1

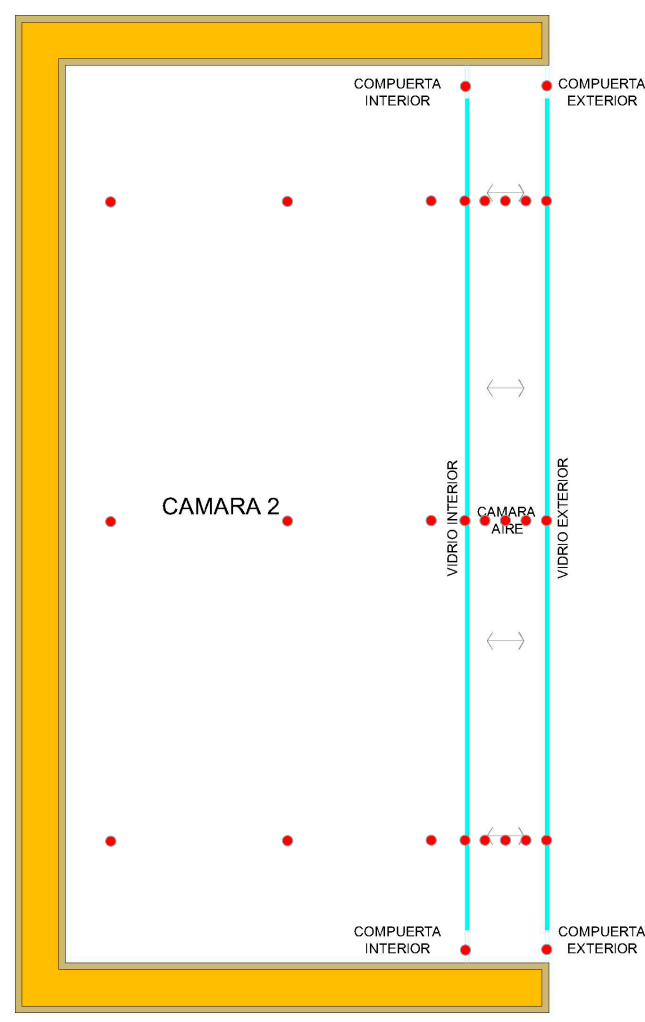

SECCION CAMARA 2

Figure 5. Sensor system. The SECCIÓN CAMARA (section or the room 1, on the left and 2, on the right) shows the section of the two rooms with the location of the sensor systems, i.e., red dots.

Wind speed needs to be measured. The distribution of anemometers consists of two vertical rows of sensors for each constructive configuration. This allows knowledge of the average speeds throughout the area. Again, only the value of air speed is not considered representative, since this variable depends on the place in which measurement is made.

The type of anemometer is the Omni-directional with hot foil, since the air direction is not known and it will change over time. These anemometers are insensitive to changes in the direction of the air, are the least influenced by temperature variations and can be easily attached to a data logger. In Figure 6, the anemometer distribution used for both prototypes is represented. The installation of a pyranometer to monitor the amount of radiation incident on the glass was also deemed important. This allows us to discard $\mathrm{T}$ increases/decreases due to a change in the amount of radiation (rather than because of the behavior of the prototype). 


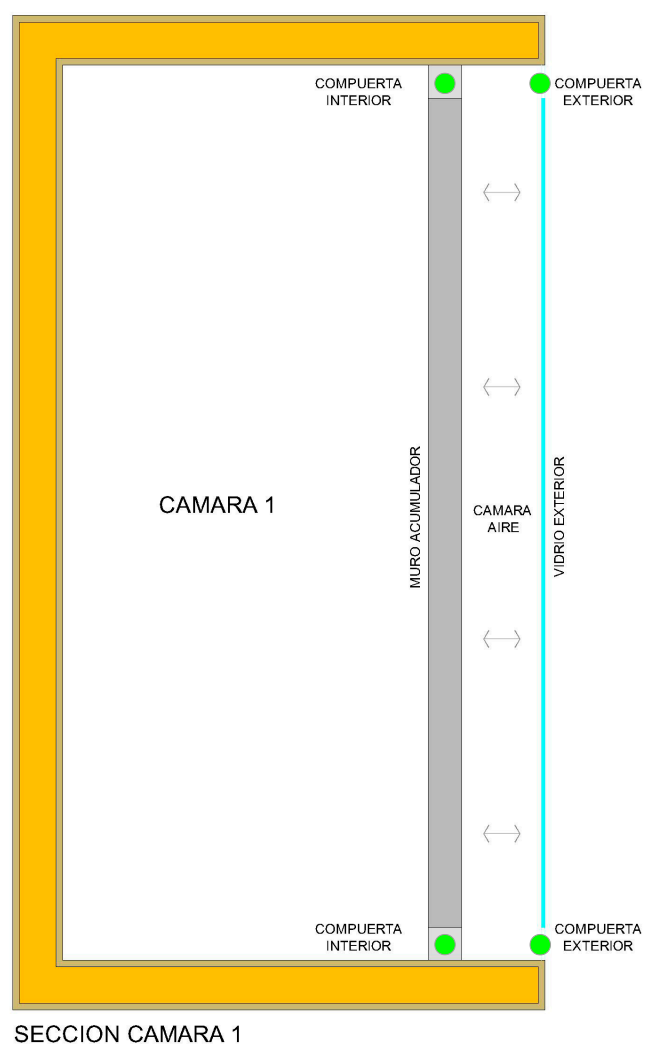

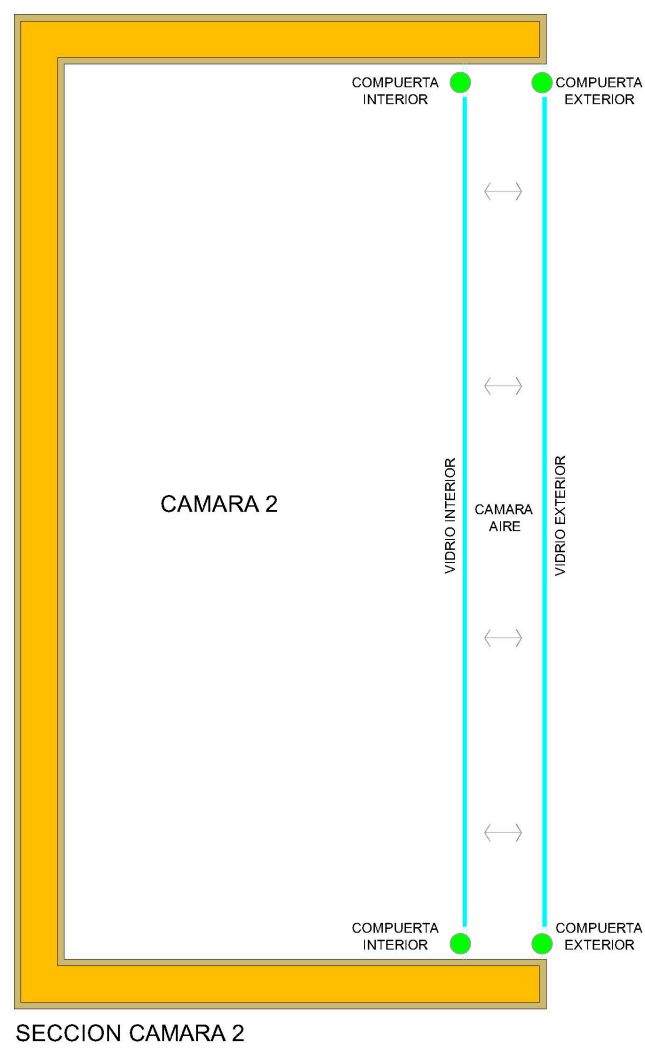

SECCION CAMARA 2

Figure 6. Distribution of the anemometers. The SECCIÓN CAMARA (section or room 1, on the left and 2 , on the right) shows the section of the two rooms with the location of the anemometers, i.e., green dots.

\subsection{Data Acquisition}

A unit is needed that registers and stores the signals coming from the sensors. This task can be accomplished in different ways depending on the number of channels and depending if continuous or punctual measures are required: from the use of simple multi-input Data Loggers to digital data acquisition units. Data obtained using the KNX system, developed by ACCIONA INFRAESTRUCTURAS were collected, see Figure 7. The monitored data were collected using the platform created by the group ACCIONA. The platform allows us to collect and export data using *.csv files for subsequent processing. The methodology used is as follows: export the needed data obtained from the different sensors, detect missing values (we found slots without data) and outliers and perform a post-processing analysis using statistical software. In Figure 8 the web monitoring system used to obtain the data is shown.

The external conditions to be analyzed are (i) temperature $\left({ }^{\circ} \mathrm{C}\right)$; (ii) $\mathrm{HR}(\%)$; (iii) Illumination (lux); (iv) Velocity $(\mathrm{m} / \mathrm{s}),(\mathrm{v})$ Rainfall $(\mathrm{mm} / \mathrm{h})$ and (vi) Radiation $\left(\mathrm{W} / \mathrm{m}^{2}\right)$. The indoor conditions that can be analyzed and studied are (i) temperature ( ${ }^{\circ} \mathrm{C}$ ); (ii) $\mathrm{HR}$ (\%); (iii) Illumination (lux); (iv) $\mathrm{CO}_{2}$ (ppm); (v) Consumption (W) and (vi) Radiation $\left(\mathrm{W} / \mathrm{m}^{2}\right)$. 


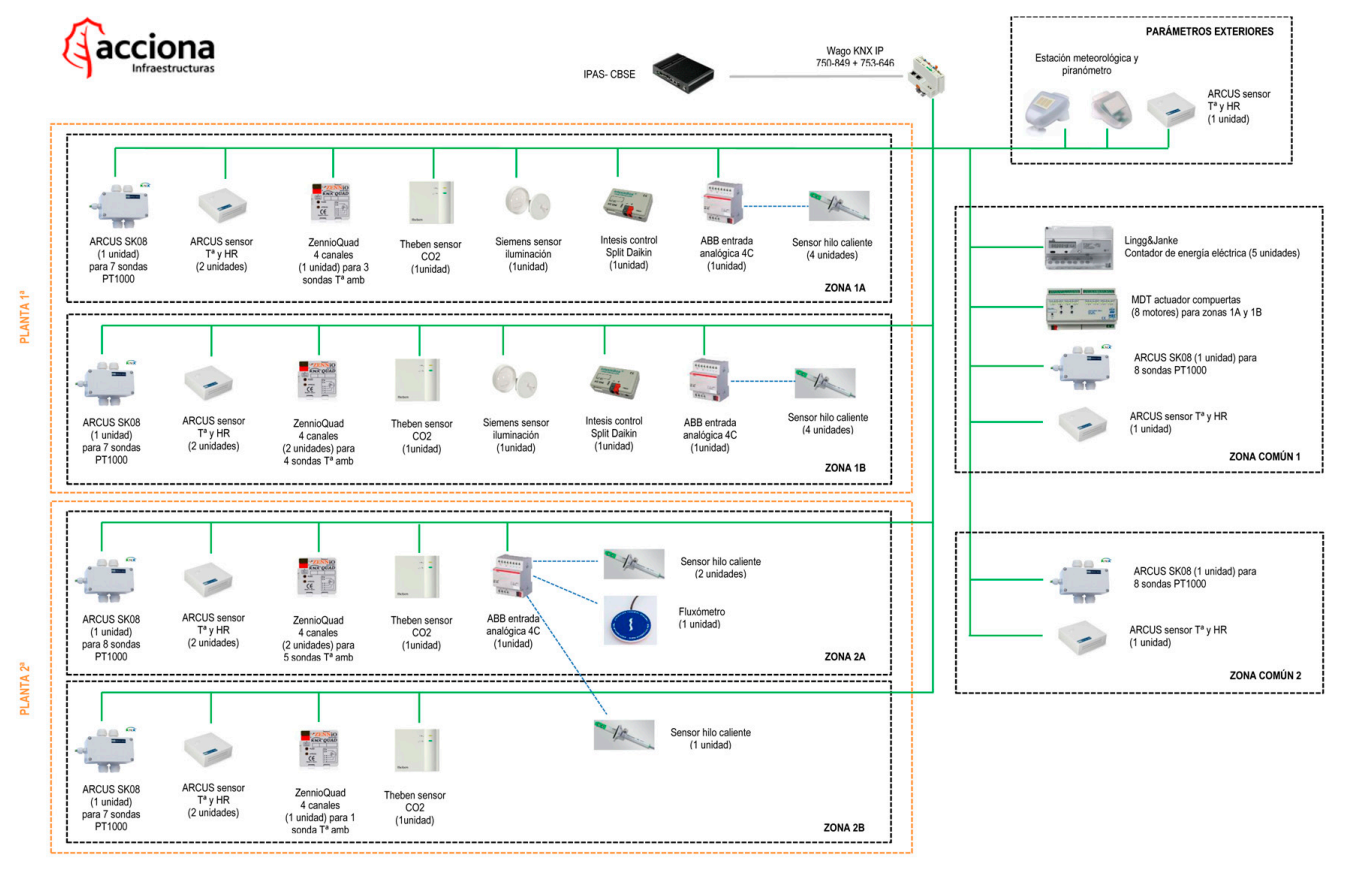

EDIFICIO DEMOSTRADOR EN SEVILLA

Figure 7. General schema of the installation in the Seville building. One can see the first roof (1A) and the second floor (2A), and the different installations used to control the building.

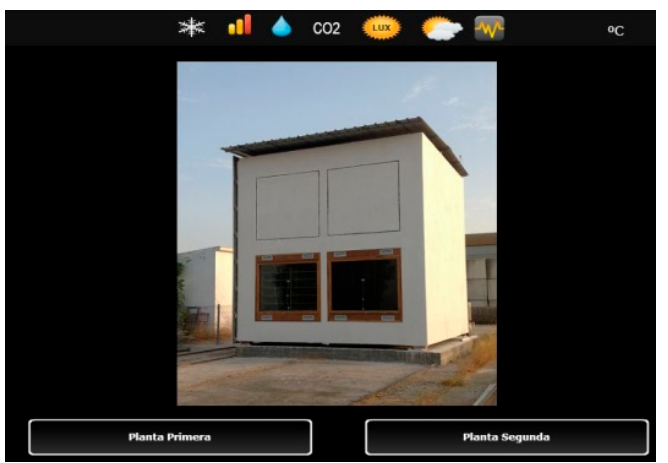

(a)

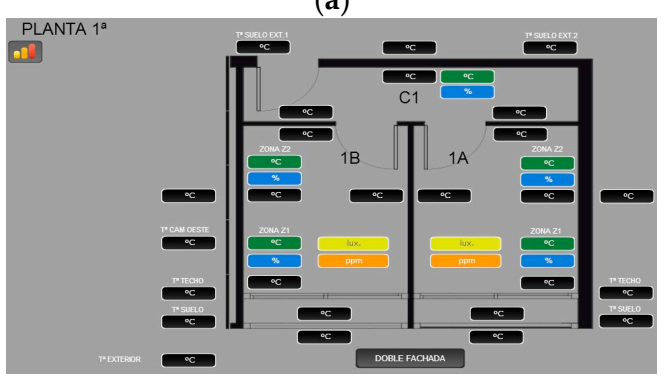

(c)

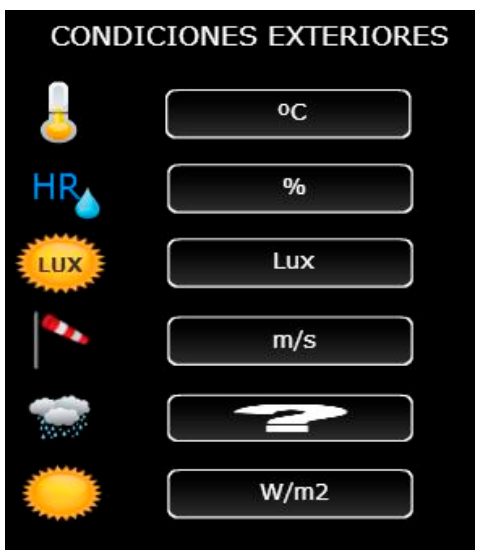

(b)

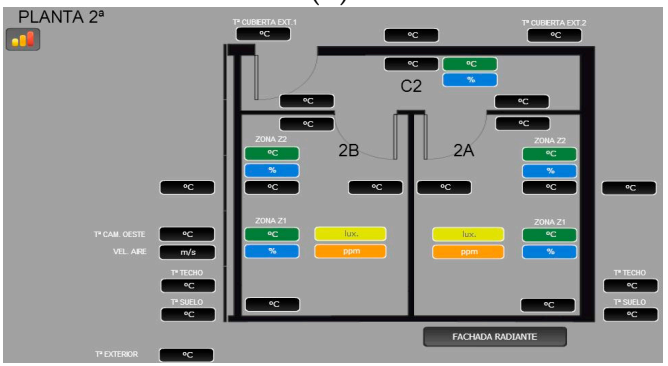

(d)

Figure 8. System monitoring via the web. On top, the access screen is shown, which allows us to select the first or the second prototype. Once a prototype is selected, one can select the different measurements (temperature, radiation, etc.). On the bottom right is the monitoring distribution for the two floors. (a) Acces screen; (b) External conditions; (c) First floor; (d) Second floor. 


\section{Solution Validation}

This section checks the similarities or differences between the models and the real prototypes. Monitored months presented in the paper are from 15 August to 15 September.

Several techniques can be applied for the validation of the solution [3,6]. The Visual Inspection of the Data and Black Box Validation, applying a set of proposed statistical methods, have been depicted.

\subsection{Visual Inspection of the Data}

The purpose is to substantiate that the model correctly represents the behavior of the system, and detect when this representation is not accurate and why. Therefore, talking with the experts and detecting possible problems in the model, or in the sensors we used to obtain the data, is needed. This analysis is needed to detect any kind of interference of external elements with the sensors, a fact that implies the introduction of some extra noise in the records.

The first thing to be considered, for a correct comparison of results, is boundary conditions, temperature, humidity, etc. In this case, temperature and solar radiation data for the period studied were consulted. Figure 9 shows the comparison between the exterior temperature for the model and for the system. We can see that, although both charts follow the same pattern, a difference in the magnitude is clear in the first few days. The deviation regarding the mean minimum temperatures of the model implies a higher daily thermal jump in the model data, compared with the system data. A detailed analysis also allows us to detect that until 21 August, the temperatures in the system were very high (compared to those obtained from the model), we discuss this later in the statistical analysis.

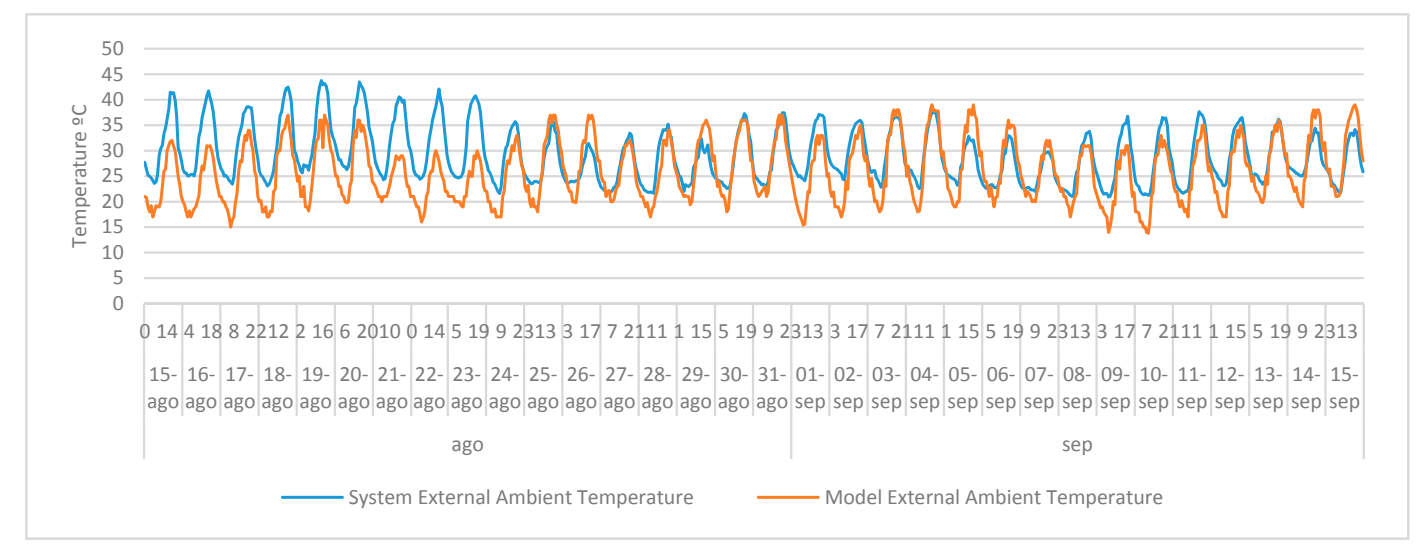

Figure 9. Exterior temperature for the system and the model.

The internal temperature depends on the external temperature and the behavior of the system (ambient temperature). Figure 10 shows the chart that depicts the comparison between the obtained data from the system and the model regarding the internal building temperature.

These differences are around $10{ }^{\circ} \mathrm{C}$ and may be due to the different boundary conditions (temperature outside the system) or, with greater probable incidence, that the model defines a bigger ventilation feedback in the chamber. Here, a deeper analysis to conclude what fails is needed. This is clearly related to the external temperature as it was detected previously. Our Model assumes a normal summer, fact that is not true for the summer of 2013 in Seville.

Another interesting element to consider is the acclimatization system. In Figure 11 the behavior of the cooling acclimatization system (analyzing the $\mathrm{kW}$ ) for the model and the system is represented. It can be seen that in the first 7 days there is a remarkable coincidence of power consumption between model and system. In the next three weeks, these values indicate a greater difference. It would be interesting to perform a study across the values of other variables, over the same period, to determine whether there is any explanation for this divergence. 


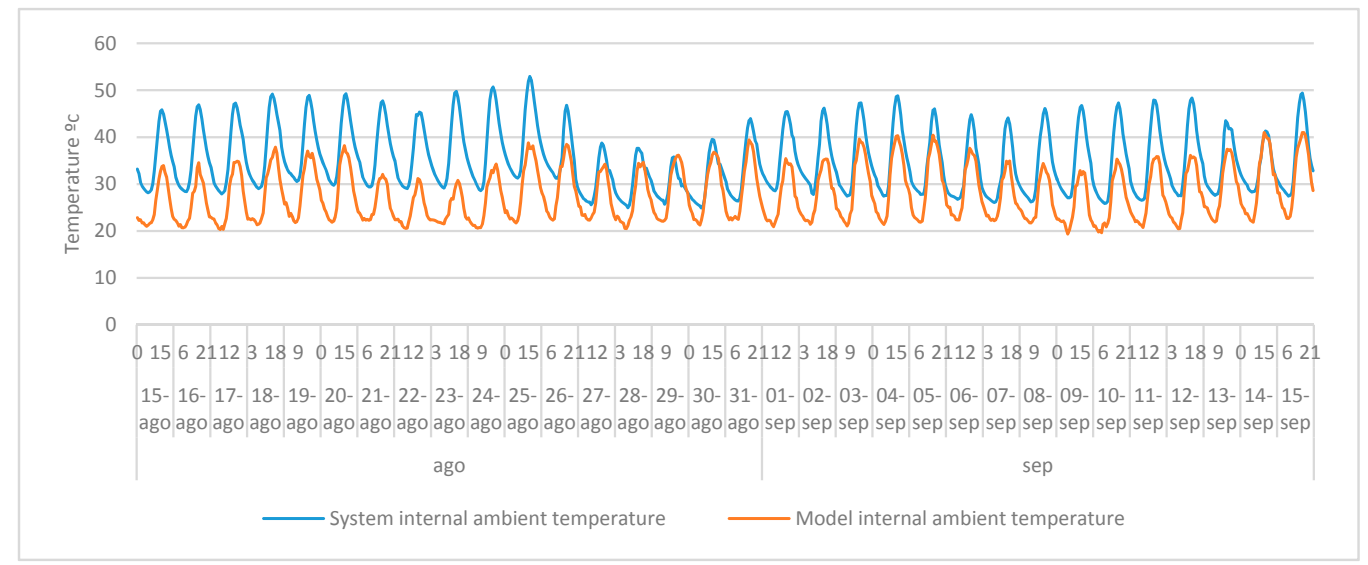

Figure 10. Internal (ambient) temperature for the building.

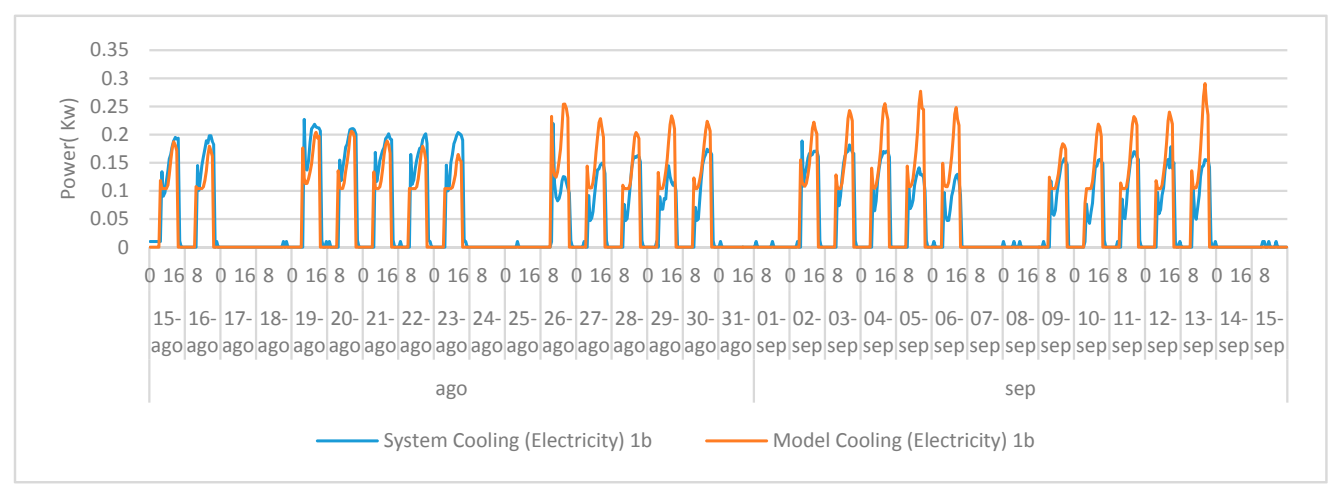

Figure 11. Module 1b. Behavior of the System and model cooling climatic system.

Regarding the horizontal radiation values for the system, they seem to be around $20 \%$ lower than those values obtained from the model. Despite the fact that there is this deviation in terms of magnitude, the fact that it is fairly homogeneous allows us to conclude that the model is accurate enough for use.

All of this graphical information and the first analysis done using the information of the experts, on both the model and the system, lead us to suggest some modifications in the model (some calibrations) and other modification on the sensors that allows us to obtain the information of the system (similar to the case of the outdoor temperature).

Other techniques can be applied here, like statistical techniques in order to understand the level of correctness to conclude, from a statistical point of view, that the model is valid.

\subsection{Statistical Analysis of the Solution}

To perform a Solution Validation, a Black Box technique can be used [4]. With this technique it is assumed that nothing is known regarding the model. Mainly the inner idea is to analyze the obtained data and compare them with the data we obtain from the system. We are focused here on the analysis of the radiation, the external and the internal temperature since these three cases present different levels of complexity regarding the validation. We are working on all tests at $95 \%$.

\subsubsection{Radiation}

We start working with Radiation, see Figure 12, obtaining the mean for every day and analyzing if the measurements we obtain in the system are equivalent to the results we previously obtained with the simulator. Applying a common Wilcoxon test [41] (we cannot assume normality of the radiation 
observations over time; hence, we cannot apply a paired $t$-test), we cannot discard the null hypotheses; hence, we can argue that both samples belong to the same population ( $p$-value is $>0.05$ ). The solution to the tests is presented here using $R$ statistical language. We compare the radiation information for the model with the data we obtained from the system.

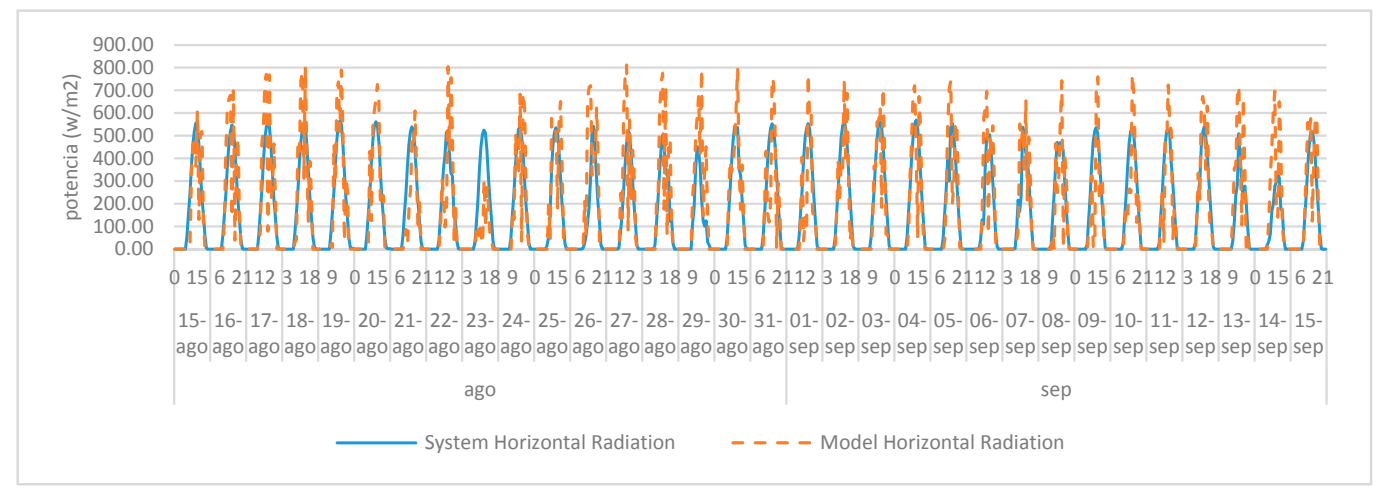

Figure 12. Horizontal radiation for the system and the model.

Wilcoxon signed rank test

data: Data.for.the.paper.by.day\$Radiation_model and

Data.for.the.paper.by.day\$Radiation_system.

$\mathrm{V}=326, p$-value $=0.2539$

Alternative hypothesis: true location shift is not equal to 0

If all the time series are analyzed, not just the mean, the obtained values support again that the null hypotheses cannot be discarded.

Wilcoxon signed rank test with continuity correction

data: Data.for.the.paper\$Radiation_model and Data.for.the.paper\$Radiation_system

$\mathrm{V}=49500.5, p$-value $=0.292$

Alternative hypothesis: true location shift is not equal to 0

In the case of radiation, the simulator patterns fit well with the pattern of the data obtained with the system, and the statistical test confirms this. Hence, it can be assumed that the simulator behaves as expected and (most important) the sensors are correctly placed.

\subsubsection{External Temperature}

The next step is to review what happens with the temperature variable. First, a comparison using the Wilcoxon test is done. In this case, analyzing the mean for every day, and comparing the results obtained from the model and the system, it is concluded that null hypotheses must be rejected.

Wilcoxon signed rank test

data: Data.for.the.paper.by.day $\$ T e m p e r a t u r e \_m o d e l$ and Data.for.the.paper.by.day $\$ T e m p e r a t u r e \_s y s t e m$ $\mathrm{V}=52, p$-value $=1.802 \times 10^{-5}$

alternative hypothesis: true location shift is not equal to 0

Hence, in the case of temperature, we cannot conclude that the model fits well with the data.

We can validate this (we do so) using historical data, but this is not the kind of validation we are presenting here. A Solution Validation must include the data we obtain from the system, to detect possible problems related to the data acquisition, implementation of the solutions or (as the last alternative) the model assumptions. As an initial step, we draw a chart, see Figure 13a, depicting 
the relation between the system and model temperatures. Analyzing the patterns, a logarithmic transformation of the data can help to smooth the relation between both variables; by doing so, the chart represented in Figure 13b has been obtained.

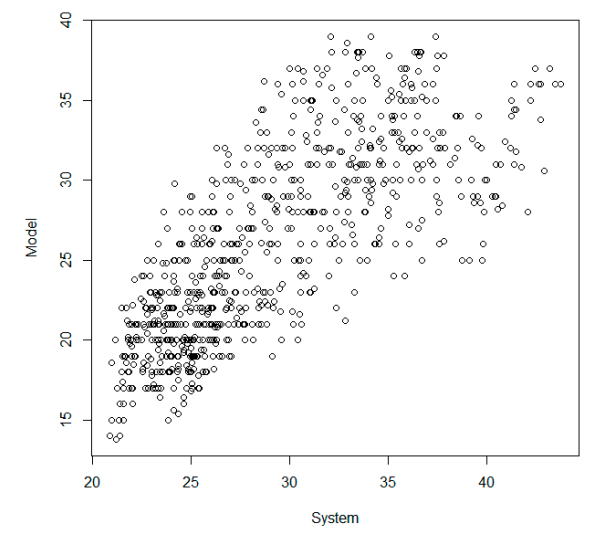

(a)

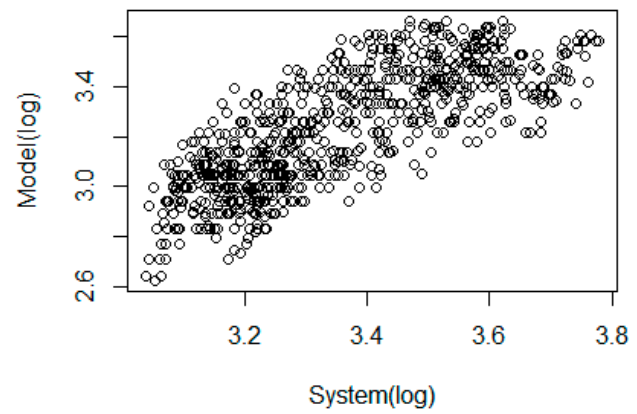

(b)

Figure 13. Plot between System and Model time series for the exterior temperature, (a) depicts the relation between the system and the model temperatures, $(\mathbf{b})$ the data with a logarithmic transformation.

Now, the represented data can be analyzed by logarithmic transformation. This analysis indicates that the data obtained from the model do not correctly fit the data obtained from the system.

Wilcoxon signed rank test

data:Data.for.the.paper.by.day\$Temperature_model_log and

Data.for.the.paper.by.day\$Temperature_system_log

$\mathrm{V}=51, p$-value $=1.603 \times 10^{-5}$

alternative hypothesis: true location shift is not equal to 0

By performing a new analysis with the logarithmic data, the results are not improved. Hence, the problem must be related to the system (the summer is unexpectedly hot), the way the data are obtained from the system (the sensors), or the model (some assumptions are not correct). The analysis of the mean temperatures for the end of August and beginning of September proves, as the validation suggests, that summer of 2013 was hotter than expected in Seville [42,43], see Figure 14.

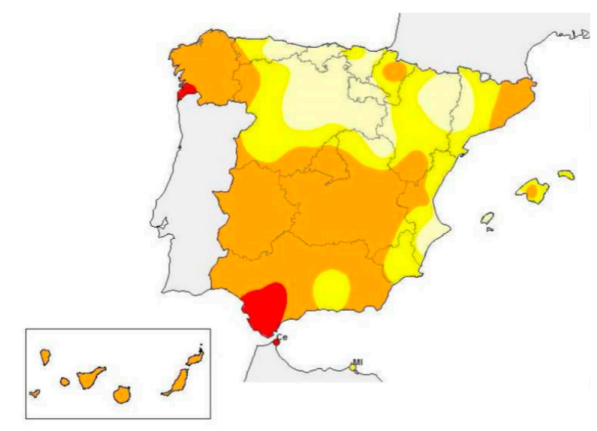

(a)

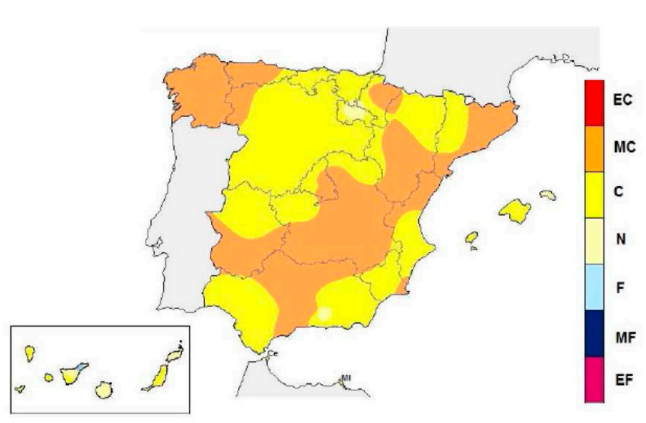

(b)

Figure 14. On the (a) is shown the August 2013 temperatures in Spain [43], on the (b) are the September 2013 temperatures [42]. Note that Seville is affected by unusually hot temperatures during the first days of august. 
Since the source of the discrepancy between model and solution data is due to the use of climatic data that assume a usual summer, we discard from the temporal series those days that are over the normal temperature, mainly prior to 21 august. Higher maximum temperatures were generally registered in the first two days of the month, at the start of the second ten days and between 18 and 21, dates on which higher values of the month, above $40{ }^{\circ} \mathrm{C}$, were reached in Extremadura and Guadalquivir. Major stations registered the following values on 19 days: Seville-airport $42.8^{\circ} \mathrm{C}$, Cordoba-Jerez de la Frontera with $41.7^{\circ} \mathrm{C}$ and Morón de la Frontera airport $42.4^{\circ} \mathrm{C}$ [43]. Moreover, the mean of the temperatures in our model was below 2.29 degrees (due to this unusually hot summer). Taking into account these adjustments to the model, we performed the test again, obtaining:

Wilcoxon signed rank test

data: Data.for.the.paper.by.day\$Temperature_model_m[x] and

Data.for.the.paper.by.day\$Temperature_system $[\mathrm{x}]$

$\mathrm{V}=190, p$-value $=0.7265$

alternative hypothesis: true location shift is not equal to 0

The purpose of the model is not to predict the external temperatures, but it must be assured that the model predicts the ambient temperature of the building (or the room temperature because this is a key aspect of comfort). In the next section, the ambient temperature validation is analyzed.

\subsubsection{Ambient Temperature}

Continuing from the visual analysis of these data that we have previously done, we detect that the temperatures we obtain in the model are low in comparison with the system temperatures. As we previously detect, this is because the summer was too hot. Specifically, the mean of the system is about 34.92, while the mean for the model is 27.72 degrees Celsius. However, in the validation of the temperature, the offset between model and system temperature was only 2.29 degrees Celsius; this implies that something else is causing this gap (despite the unusualy hot summer). Reviewing the model assumptions, we detect that the ventilation of the building is quite high, causing a hyperventilation of the building. We modify our model according to these findings. The question that arises is if the obtained model data chart shapes (the curves, not the magnitudes) are correct despite this error.

Again, discarding the data prior to 21 August due to the unusual behavior of the temperature and considering the offset due to the hyperventilation for the chamber, we obtain:

Wilcoxon signed rank test

data: Data.for.the.paper.by.day\$Ambient_model_m[x] and

Data.for.the.paper.by.day\$Ambient_system[x]

$\mathrm{V}=182, p$-value $=0.8809$

alternative hypothesis: true location shift is not equal to 0

Clearly this shows that there is a relation between the model output and the system allowing us to validate the solution (the placement of the sensors, the new model hypotheses and the construction process performed).

\subsection{Granger Causality}

The daily means of the ambient temperature are analyzed, but the behavior of the whole shape of the time series must be also analyzed. The presence of Granger causality [44] does not assure a cause-effect relation. It may be that a third element exists that is not represented in the data that causes this. However, it is enough to determine that a relation exists between the two-time series. Hence, it can be concluded that the simulation output of the model can be used to analyze suitable alternatives in the system. "Granger causality tests are based on the notion of predictability, in particular whether past 
values of a variable $X$ contain statistically meaningful information about current values of variable $Y$ that is not contained implies the presence of a statistical causal ordering". The application of Granger causality to environmental models was done first to analyze the anthropogenic influence on global temperature.

We can apply this test to understand if the system Ambient temperature can be predicted using the model Ambient temperatures. This helps in the determination of upcoming configurations of the façade parameters.

Applying this test to the complete dataset, we obtain:

Granger causality test

Model 1:

Data.for.the.paper.by.day $\$$ Ambient_system $[\mathrm{x}]$

$\sim$ Lags(Data.for.the.paper.by.day\$Ambient_system[x], 1:1) +

Lags(Data.for.the.paper.by.day\$Ambient_model_m[x], 1:1)

Model 2:

Data.for.the.paper.by.day $\$$ Ambient_system[x]

$\sim \operatorname{Lags}$ (Data.for.the.paper.by.day\$Ambient_system[x], 1:1)

Res.Df Df F $\operatorname{Pr}(>\mathrm{F})$

122

$223-12.90190 .1026$

and

Granger causality test

Model 1:

Data.for.the.paper.by.day $\$ A m b i e n t \_m o d e l \_m[x]$

$\sim$ Lags(Data.for.the.paper.by.day\$Ambient_model_m[x],

1:1)+Lags(Data.for.the.paper.by.day $\$$ Ambient_system[x], 1:1)

Model 2:

Data.for.the.paper.by.day\$Ambient_model_m[x]

$\sim \operatorname{Lags(Data.for.the.paper.by.day\$ Ambient\_ model\_ m[x],1:1)~}$

Res.Df Df F Pr $(>F)$

122

$223-10.2040 .6559$

Meaning that the model data have a G-causal relation with the data we obtain for the system. From the point of view of the model validation, this assures there exists a relation between both time series. Going further, and considering that the model is based on time series and the model and the system must be related, a Robust Rank Correlation Coefficient and a Corresponding Test (implemented on the ROCOCO R package) can be performed [44]. This test indicates that between both time series there clearly exists a correlation, showing that the model is representing the behavior of the system at some level of correctness.

Robust Gamma Rank Correlation:

data: Data.for.the.paper.by.day $\$ A$ mbient_system $[\mathrm{x}]$ and

Data.for.the.paper.by.day\$Ambient_model_m [x] $($ length $=26)$

similarity: linear

$\mathrm{rx}=0.2537676 / \mathrm{ry}=0.2722265$

t-norm: $\min$

alternative hypothesis: true gamma is not equal to 0

sample gamma $=-0.03597242$ 
estimated $p$-value $=0.824$ (824 of 1000 values)

This new analysis increases the confidence in the model, understanding that the Solution Validation achieves its main goals: test the model hypotheses, test the placement of the sensors, and test the construction process that has been followed to implement the proposed alternatives obtained from the simulation models.

\section{Discussion}

In the previous section, the Solution Validation for a small subset of the obtained data in the project has been shown. This validation helps us to detect problems in the hypotheses (the model) in the sensors (placement or monitoring errors) or in the boundary conditions (an unusually hot summer). Regarding this, it was quite interesting to detect that the external temperature has (as we suppose) a great impact on the models. This validation helps us to detect errors in the sensor placement and hypotheses. As shown in Section 4.1, some hypotheses lead us to obtain low temperatures for the ambient temperatures of the prototypes.

Visual inspection is a great tool to understand and detect discrepancies between the model and the system; see Figure 9. This visual inspection helps us to understand that the summer temperatures were unusually high, and we are able to corroborate this through a deeper analysis using historic climatic data.

Analogously, it is quite interesting that the model behaves as expected when the boundary conditions are usual; this is the case of radiation, which was normal in Spain, and the solution validation corroborates this. See Figure 15 to see the radiation in Spain for the selected period.

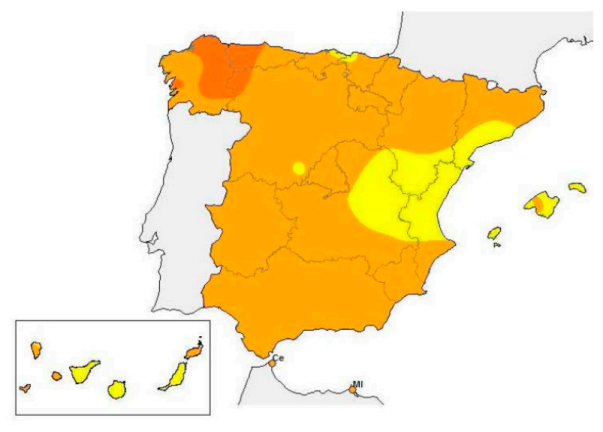

(a)

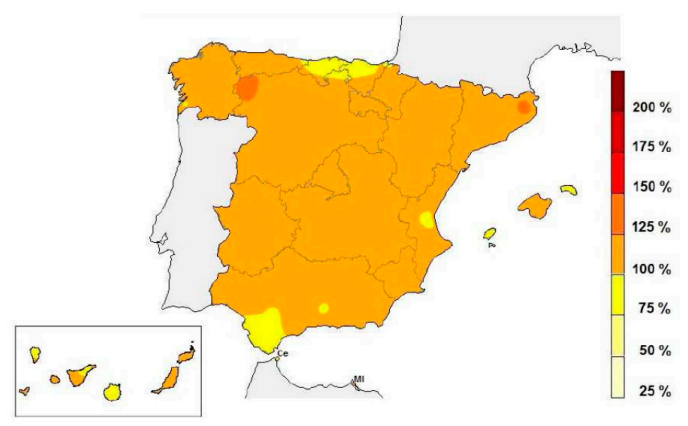

(b)

Figure 15. On the (a) is shown the August 2013 radiation on Spain [43], on the (b) is the September 2013 radiation [42].

Some interesting conclusions were obtained: the visual inspection of the data led us to understand that the general behavior of the models and the system are quite similar, a fact that led us to consider that the implementation accurately reflects the hypotheses for the model.

The model is sensitive (as it was supposed) to the boundary conditions (temperature, radiation, etc.). This implies that the ambient temperatures have the same patterns (as has been proved using the ROCOCO and Granger tests) but with a displacement in the vertical axis (due to the unusual boundary conditions discussed here). It is quite interesting that the detection of the hyperventilation in the chamber is due to an incorrect configuration.

According to the analyzed data (summer time), the operation at the level of energy demand for both façades (photovoltaic façade and double façade with lamas) is similar. It is worth mentioning that the façade with slats (the analyzed here), which allows us to control direct solar light, and its results could have been better if the air volume ventilation between outside and the air chamber would have been higher (allowing a better renewal of air and, thus, avoiding pockets of heat accumulated during the day in the chamber). According to the validation, the slats would serve to collect and capture solar 
heat, accumulate it and expel it to the interior of the room, helping to heat the room; the thermal time delay is already established, in part, with these results.

According to this validation, the model of the new façades accurately represents the ambient temperature of the building; we can use it to parameterize and propose alternatives prior to constructing a new building to achieve the comfort needed, see Table 1 .

\section{Concluding Remarks}

In this paper, a Solution Validation case study has been shown. This case of validation is rare mainly because it must be done once a decision has been made regarding system belief in the simulation results and its recommendations are applied (implemented) in the system. This paper represents a case study that can be shown as an example of a complete Solution Validation. In this case study, we propose using some specific statistical techniques in order to establish a correspondence between the time series that are provided by the model and by the monitored system. This allows us to understand if the model accurately represents the system expected behavior, taking into account the considered hypotheses.

The recalibration of the models due to the solution validation was successful, allowing the subsequent use of models in different climatic zones. In addition, the model can be adjusted further, since the slots of the air conditioning system, ventilation air volume, the mass of lamas and climate data are not completely coincidental. However, it has been corroborated that the final implementation of the system, following the directions proposed for the model results, is effective, efficient and produces important savings of time and money.

Solution Validation helps in the needed continuous Accreditation of the simulation model, becoming a key element to understand possible mistakes in the hypotheses of the model with respect to its codification or in the process followed to implement the solution. Those aspects are key elements if the simulation model is going to be used several times to define new and good solutions for other equivalent, or similar, systems. The main drawbacks of solution Validation are related to the time needed to perform such analysis once the project has been Accredited, meaning that the contractor believes in the accuracy of the model. However, if the model must be used as an element to make decisions in new scenarios, this kind of Validation must be considered as a substantial part of the whole simulation study.

Acknowledgments: This work is part of the project JSEED, Japan-Spain Energy Efficient Development for ultra-low Energy Buildings, an agreement between Spain and Japan, funded partially by CDTI. We appreciate the support of ACCIONA and the in Lab FIB and Summ Lab of the Polytechnics University of Catalonia-Barcelona Tech.

Author Contributions: Pau Fonseca i Casas and Antoni Fonseca i Casas conceived and designed the experiments and the validation process, Nuria Garrido-Soriano and Alfonso Godoy helped in the data analysis, Carolina Pujols and Jesus Garcia enabled access to the data of the building and the analysis tools.

Conflicts of Interest: The authors declare no conflict of interest. The founding sponsors had no role in the design of the study; in the collection, analyses, or interpretation of data; in the writing of the manuscript, and in the decision to publish the results.

\section{Nomenclature}

Accreditation The process in which certification of competency or credibility for the simulation model is presented.

CFD Computational Fluid Dynamics.

JSEED Japan-Spain Energy Efficient Development for Ultra-Low Energy Buildings

Validation The process to assure that a model is correct.

Verification The process to assure that a model is correctly implemented. 


\section{References}

1. ACCIONA Japan-Spain Energy Efficient Development for Ultra-Low Energy Buildings. Available online: http://www.acciona-infraestructuras.es/innovacion/area-ecoeficiencia-y-sostenibilidad/jseed. aspx?pag=\&desde=8429 (accessed on 12 June 2015).

2. Avada. The Need 4b Partner Acciona Tests Building Components within the Test Cell Project. Available online: http:/ / need4b.eu/?p=13969\&lang=sv (accessed on 23 November 2017).

3. Sargent, R. Verification and validation of simulation models. In Proceedings of the 2009 Winter Simulation Conference (WSC), Austin, TX, USA, 13-16 December 2009; Volume 37, pp. 177-183.

4. Sargent, R.G. Verification and validation of simulation models. J. Simul. 2013, 7, 12-24. [CrossRef]

5. Sargent, R.G. An interval statistical procedure for use in validation of simulation models. J. Simul. 2015, 9, 232-237. [CrossRef]

6. Balci, O. Golden rules of verification, validation, testing, and certification of modeling and simulation applications. SCS MES Mag. 2010, 4, 1-7.

7. Balci, O. Verification, validation, and certification of modeling and simulation applications. In Proceedings of the 2003 Winter Simulation Conference, New Orleans, LA, USA, 7-10 December 2003; pp. 150-158.

8. Jabri, S.; El Koursi, E.M.; Bourdeaud'huy, T.; Lemaire, E. European railway traffic management system validation using UML/Petri nets modelling strategy. Eur. Transp. Res. Rev. 2010, 2, 113-128. [CrossRef]

9. Specification and Description Language (SDL). Available online: http://www.sdl-forum.org/SDL/ Overview_of_SDL.pdf (accessed on 12 June 2015).

10. Robinson, S. Simulation verification, validation and confidence: A tutorial. Simul. Trans. Soc. Model. Simul. Int. 1999, 16, 63-69.

11. Robinson, S.; Brooks, R.J. Independent verification and validation of an industrial simulation model. Simul. Trans. Soc. Model. Simul. Int. 2010, 86, 405-416. [CrossRef]

12. Vedrenne, M.; Borge, R.; Lumbreras, J.; Rodríguez, M.E. Advancements in the design and validation of an air pollution integrated assessment model for Spain. Environ. Model. Softw. 2014, 57, 177-191. [CrossRef]

13. Lopes, J.; Silva, C.; Cardoso, A. Validation of a water quality model for the Ria de Aveiro lagoon, Portugal. Environ. Model. Softw. 2008, 23, 479-494. [CrossRef]

14. Kersebaum, K.C.; Boote, K.J.; Jorgenson, J.S.; Nendel, C.; Bindi, M.; Frühauf, C.; Gaiser, T.; Hoogenboom, G.; Kollas, C.; Olesen, J.E.; et al. Analysis and classification of data sets for calibration and validation of agro-ecosystem models. Environ. Model. Softw. 2015, 72, 402-417. [CrossRef]

15. Sarrazin, F.; Pianosi, F.; Wagener, T. Global Sensitivity Analysis of environmental models: Convergence and validation. Environ. Model. Softw. 2016, 79, 135-152. [CrossRef]

16. Liu, C.; Li, A.; Yang, C.; Zhang, W. Simulating air distribution and occupants' thermal comfort of three ventilation schemes for subway platform. Build. Environ. 2017, 125, 15-25. [CrossRef]

17. Tan, B.; Yavuz, Y.; Otay, E.N.; Çamlıbel, E. Optimal selection of energy efficiency measures for energy sustainability of existing buildings. Comput. Oper. Res. 2016, 66, 258-271. [CrossRef]

18. Chang, K.H. A decision support system for planning and coordination of hybrid renewable energy systems. Decis. Support Syst. 2014, 64, 4-13. [CrossRef]

19. Mattiussi, A.; Rosano, M.; Simeoni, P. A decision support system for sustainable energy supply combining multi-objective and multi-attribute analysis: An Australian case study. Decis. Support Syst. 2014, 57, 150-159. [CrossRef]

20. Lei, H.; Wang, R.; Zhang, T.; Liu, Y.; Zha, Y. A multi-objective co-evolutionary algorithm for energy-efficient scheduling on a green data center. Comput. Oper. Res. 2016, 75, 103-117. [CrossRef]

21. Palonen, M.; Hasan, A.; Siren, K. A genetic algorithm for optimization of building envelope and hvac system parameters. In Proceedings of the 11th IBPSA Conference, Glasgow, UK, 27-30 July 2009; pp. 159-166.

22. Cai, Y.; Sanstad, A.H. Model uncertainty and energy technology policy: The example of induced technical change. Comput. Oper. Res. 2016, 66, 362-373. [CrossRef]

23. Patiño-Cambeiro, F.; Bastos, G.; Armesto, J.; Patiño-Barbeito, F. Multidisciplinary Energy Assessment of Tertiary Buildings: Automated Geomatic Inspection, Building Information Modeling Reconstruction and Building Performance Simulation. Energies 2017, 10, 1032. [CrossRef]

24. Ma, Y.; Saha, S.; Miller, W.; Guan, L. Comparison of Different Solar-Assisted Air Conditioning Systems for Australian Office Buildings. Energies 2017, 10, 1463. [CrossRef] 
25. Blanco, J.M.; Arriaga, P.; Rojí, E.; Cuadrado, J. Investigating the thermal behavior of double-skin perforated sheet façades: Part A: Model characterization and validation procedure. Build. Environ. 2014, 82, 50-62. [CrossRef]

26. Parra, J.; Guardo, A.; Egusquiza, E.; Alavedra, P. Thermal performance of ventilated double skin façades with venetian blinds. Energies 2015, 8, 4882-4898. [CrossRef]

27. EU Directive 2010/31/EU of the European Parliament and of the Council of 19 May 2010 on the energy performance of buildings. Off. J. Eur. Union 2010, 13-35. [CrossRef]

28. International Energy Agency (IEA). Energy Efficiency Market Report; IEA: Paris, France, 2014; ISBN 978-92-64-21826-0.

29. Salom, J.; Widén, J.; Candanedo, J.A.; Sartori, I.; Voss, K.; Marszal, A.J. Understanding Net Zero Energy Buildings: Evaluation of load matching and grid interaction indicators. Proc. Build. Simul. 2011, 6, 14-16.

30. Sartori, I.; Napolitano, A.; Voss, K. Net zero energy buildings: A consistent definition framework. Energy Build. 2012, 48, 220-232. [CrossRef]

31. IDEA. Guía Técnica Condiciones Climáticas Exteriores de Proyecto; IDEA: Madrid, Spain, 2010.

32. Weather Data All Regions: Europe WMO Region 6. Available online: https://energyplus.net/weatherregion/europe_wmo_region_6 (accessed on 23 November 2017).

33. Ministerio de la Presidencia. Available online: http://documentos.060.es/legislacion/common/34073.pdf (accessed on 23 November 2017).

34. Fomento, M. de Código Técnico de la Edificación. Available online: http://www.fomento.gob.es/mfom/ lang_castellano/direcciones_generales/arq_vivienda/_informacion/normativa/CodigoEdificacion.htm (accessed on 23 November 2017).

35. Molina, C.G. Alternativas Para la Mejora de la Eficiencia Energética de Los Acristalamientos: Los Vidrios Dinámicos. Ph.D. Thesis, Universidad Politécnica de Madrid, Madrid, Spain, 2011.

36. Fonseca i Casas, P.; Fonseca i Casas, A.; Garrido-Soriano, N.; Casanovas, J. Formal simulation model to optimize building sustainability. Adv. Eng. Softw. 2014, 69, 62-74. [CrossRef]

37. Ortiz, J.; Fonseca, A.; Salom, J.; Garrido, N.; Fonseca, P.; Russo, V. Comfort and economic criteria for selecting passive measures for the energy refurbishment of residential buildings in Catalonia. Energy Build. 2016, 110, 195-210. [CrossRef]

38. Ortiz, J.; Fonseca i Casas, A.; Salom, J.; Garrido Soriano, N.; Fonseca i Casas, P. Cost-effective analysis for selecting energy efficiency measures for refurbishment of residential buildings in Catalonia. Energy Build. 2016, 128, 442-457. [CrossRef]

39. Fonseca i Casas, P. SDL distributed simulator. In Proceedings of the 2008 Winter Simulation Conference, Global Gateway to Discovery-WSC, Miami, FL, USA, 7-10 December 2008.

40. Energy Plus. Input Output Reference: The Encyclopedic Reference to Energy Plus Input and Output. Available online: https:/ / energyplus.net/sites/default/files/pdfs/pdfs_v8.3.0/InputOutputReference.pdf (accessed on 23 November 2017).

41. Wilcoxon, F. Individual comparisons of grouped data by ranking methods. J. Econ. Entomol. 1946, $39,269$. [CrossRef] [PubMed]

42. Granger, C.W.J. Investigating Causal Relations by Econometric Models and Cross-spectral Methods. Econometrica 1969, 37, 424. [CrossRef]

43. Kaufmann, R.; Stern, D. Evidence for human influence on climate from hemispheric temperature relations. Nature 1997, 388, 39-44. [CrossRef]

44. Bodenhofer, U.; Krone, M.; Klawonn, F. Testing noisy numerical data for monotonic association. Inf. Sci. 2013, 245, 21-37. [CrossRef]

(C) 2017 by the authors. Licensee MDPI, Basel, Switzerland. This article is an open access article distributed under the terms and conditions of the Creative Commons Attribution (CC BY) license (http:/ / creativecommons.org/licenses/by/4.0/). 